\title{
化学与人类文明通识课中的思政教育 一以法为圭臬育新人
}

\author{
谢旻轩, 邹培杰, 徐伟明* \\ 杭州师范大学材料与化学化工学院，杭州 311121
}

\begin{abstract}
摘要: 利用化学通识课程平台, 通过合作式课堂使化学知识与法治精神碰撞交融, 同时结合案例融合法治和思政教 育, 从正反两方面让学生发现化学对于人类文明的基础性和重要性, 培养学生的责任感和法治精神, 敬畏化学、用 好化学、管好化学, 以法为圭香, 培育新时代青年。
\end{abstract}

关键词：通识教育；法治；思政教育；以法为圭香；育新人

中图分类号: G64; O6

\section{Ideological and Political Education in General Education Course of Chemistry and Human Civilization: Nurturing New Talent with the Spirit of the Rule by Law}

\author{
Wenxuan Xie, Peijie Zou, Weiming Xu * \\ College of Material, Chemistry and Chemical Engineering, Hangzhou Normal University, Hangzhou 311121, China.
}

\begin{abstract}
Using the platform of chemistry general education course, the knowledge of chemistry and the rule of law can be blended through cooperative classroom. At the same time, legal education, ideological and political education are integrated with cases. Students could find the foundation and importance of chemistry for human civilization from both positive and negative aspects. It also cultivates students' sense of responsibility and spirit of rule of law, and makes students revere chemistry, make good use of chemistry and manage chemistry well. By taking law as the standard, we nurturing new talent in the new era.
\end{abstract}

Key Words: General education; The rule by law; Ideological and political education; In the eyes of the law; Nurturing new talent

化学已经以各种形式深深融入了我们的生活, 可以说现代社会的每一个角落, 都带有化学深深 的痕迹与烙印, 这些印记昭示着化学对人类文明的卓越贡献。然而, 20 世纪由化学污染引起的 “八 大公害” 事件, 我国的三聚氧胺事件, 黎巴嫩首都贝鲁特港口硝酸铵剧烈爆炸事故等化学危害事件 的发生, 为化学及其相关行业的健康发展蒙上了阴霘。党的十八大以来, 我国大力推进国家治理能 力和治理体系现代化, 进一步全面贯彻依法治国 ${ }^{[1,2]}$ 。面对化学技术的发展现状, 我们对于化学及其 相关行业的治理, 也必须依法治理, 而治理的走深走实必须依靠一批既有一定化学素养又有较强法 治精神的新青年。以法为圭臬, 通过化学与法学体系的交融, 我们选取国内外典型的化学品安全事

收稿: 2020-11-26; 录用: 2021-01-21; 网络发表: 2021-01-22

“通讯作者, Email: wmxu@zju.edu.cn

基金资助: 浙江省高等教育 “十三五” 第二批教学改革研究项目(jg20190389); 杭州师范大学教改项目 
故进行剖析, 发现这些事故背后从业人员法治精神缺失的现状值得警醒。因此, 我们依托通识课 程一一化学与人类文明这一平台, 通过案例分析和合作式课堂, 在化学通识课程中融入法治教育和 思政教育 ${ }^{[3]}$, 对未来工作中可能从事化学相关行业工作的大学生打一剂思想上的预防针, 进一步培 养当代大学生的使命感和责任感, 达到积极的思政教育的目的。

\section{1 化学与人类文明}

从我们的远古祖先学会钻木取火, 到现在人们用电灯照亮夜幕; 从古希腊哲学家运用朴素唯物 主义思考世界的本源, 到今天我们认识到分子是保持物质物理化学特性的最小单元; 从中华民族开 始用孔雀石等矿石铸造出精美绝伦的青铜器, 到今天高分子材料的应用改变了现代社会的样貌, 人 类文明演变发展的历史就是与化学进步紧密联系的历史 ${ }^{[4]}$ 。化学, 究其本意为 “变化之学”, 这是充 满了人类对于世界的好奇、求知欲和探索实践的一门学问。

近代以来人类社会发生了翻天覆地的变化, 在这飞跃之中, 化学作为最重要的基础学科之一, 推动了生产力的发展 ${ }^{[5]}$ 。1908年, 德国化学家哈伯(F. Haber, 1868-1934)使得合成氨反应产率达到惊 人的 $8 \%$, 自此氨的工业产率大大提升, 为农业提供了充足的化肥。现在沿着哈伯的道路, 合成氨工 业仍在不断发展, 人类拥有了充足的 “面包” 得以思考星辰大海的来路。1928年, 英国细菌学家弗 莱明(A. Fleming, 1881-1955)发现了青霉素, 自此开启了运用抗生素的序幕。当下靶向药物、手性药 物等前沿领域的研究不断深入, 药物化学的发展极大地提升了人类的健康水平, 人类得以用更高质 量的生命去创造自我的价值。仅从化学肥料和化学药物这两个领域的发展, 我们就能看出化学对于 人类文明做出的举足轻重的卓越贡献, 更不必说生活的方方面面了。

通过化学与人类文明通识课程的学习, 我们会发现各种化学产品早已如春风润雨般渗透、滋养 着我们的人类文明。人类离不开化学, 化学也在化学家的实践中不断发展成熟, 可以说化学是推动 现代经济与社会发展的强大杜杆。改革开放以来, 我国化工行业迅猛发展, 形成了较为完备的化学 工业体系, 目前已成为世界化学品生产和消费大国。同时, 问题也随之而来: 化学品在食品中的非 法添加、滥用; 化学品生产、储存、运输不当导致的安全事故; 有毒有害化学品的监管存在漏洞等 等, 这些问题使得化学成为普通民众眼中谈之色变的 “猛虎” 。但其实这些问题的出现, 并不应完 全归各于化学, 而是涉事企业或个人既不具备足够的化学知识, 更缺乏法治精神, 才导致了恶性事 件的发生。

马克思曾指出, 任何事物都是一个内部对立统一的矛盾共同体, 这就要求我们用辩证的眼光看 待化学, 正视化学的两面性, 正视化学技术现下面临的危机。我们依托化学通识课程的平台, 不仅 要让其他学科的学生认识到化学科技的正向性, 更要深刻地认识到它的两面性, 敬畏化学、用好化 学、管好化学, 使其为经济社会的可持续发展服务。而这就要求我们在化学通识课程教学中融入法 律的观念、法治的精神, 在传授知识的同时健全学生的思想根基, 为学生树立好法治精神和底线思 维, 提前指明道德与法律的底线。

\section{2 化学品安全事件与从业者法治精神的缺位}

\section{1 中国奶制品污染事件}

2008年中国奶制品污染事件被曝光后震惊全国, 谁也没想到, 在21世纪的中国还会发生这样令 人发指的食品安全事件, 违规化学添加剂的魔爪, 竟伸向了婴幼儿的奶粉。

三聚氭胺, 俗称密胺、蛋白精, 是一种含氮量很高的常用化工原料。三聚氭胺常用于表面涂料 行业, 可以与甲醛发生缩聚反应, 生成三聚氰胺树脂, 该树脂广泛作为金属涂料、纺织物的防褶皱 处理剂。这样一种与食品难以联系到一起的物质, 不法分子却利用国家食品药品监管部门对奶制品 采用的检测方法—— “凯式定氮法” 的漏洞 ${ }^{6]}$, 使其成为了当时部分奶粉企业之间心照不宣的 “食品 添加剂”。《农产品质量安全法》第二十四条规定, 农产品生产企业和农民专业合作经济组织应当 
建立农产品生产记录, 如实记载使用农业投入品的名称、来源、用法、用量和使用、停用的日期[7], 不 法奶农无视这一法律规定, 并且违反 《食品卫生法》第九条(2009年6月1日起废止) ${ }^{[8]}$, 利用漏洞恶意 添加非食品用化学物质一三聚氧胺, 事件经过调查后三名奶农被判处死刑。而在食品卫生的监管 上, 是由县级以上地方人民政府卫生行政部门对食品进行定期或者不定期的抽样检验, 部分不法经 营者通过行贿等方式躲避了严格规范的监管, 使得问题产品在市场中畅通无阻。他们行贿受贿的行 为也同时触犯 《刑法》第八章贪污贿赂罪 ${ }^{[9]}$, 三鹿集团前董事长被判处无期徒刑, 负有责任的领导官 员被问责免职, 形成了一股 “行政问责与司法问责风暴” 。这起事件从化学品的非法添加开始, 也 推动了我国立法上的变革, 新的《食品安全法》 ${ }^{[10]}$ 更加细化, 加大了处罚力度, 更加全面的保障人 民的食品安全。这起事件中, 从奶农的原奶生产到奶企的奶制品加工销售再到政府机构的检测监管 环节, 各类不法分子混杂其中, 他们思想根基浅薄, 法制精神贯乏, 并且不清楚非法添加非食品用 化学物质的危害, 只看得见自己的利益。

通过这一案例, 我们引导学生发现, 在看似平静的牛奶市场上, 实则有着波涛汹涌的竞争, 在 过去市场秩序混乱、垄断盛行的情况下, 竞争愈发激烈艰辛: 奶农不惜非法添加非食品用化学物质 以便销售低品质原奶给奶企; 各大企业为追求市场、利益, 明知产品存在问题, 不惜用经济利益腐 蚀官员, 盲目追求经济利润、忽略产品品质, 进一步混乱了市场秩序。这是一种法治精神的匮乏, 是利益本位主义的盛行 ${ }^{[11]}$ 。对于通识课程而言, 如果学生们未来的工作中可能涉及到食品安全问题 或化学品的监管使用, 必须使得他们清楚化学物质有自己的性质和作用, 绝对不能滥用, 心中要有 理想信念，坚守道德和法律的底线，不能为了追求个人利益造成全社会的巨大损失。

\section{2 黎巴嫩首都爆炸事故}

我们在最近的教学中使用的另一起典型事件是2020年的黎巴嫩首都爆炸事故, 这起爆炸产生的 地震波相当于里氏 3.3 级地震, 造成了重大人员伤亡和黎巴嫩的时局动荡。初步调查显示, 该港口的 12 号仓库内除了发生爆炸的 2750 吨硝酸铵, 还存放了大量的易燃易爆物。

硝酸铵 $\left(\mathrm{NH}_{4} \mathrm{NO}_{3}\right)$, 呈无色无臭的透明晶体或白色晶体, 一般用于化肥和化工原料。纯硝酸铵在 常温下是稳定的, 对打击、碰撞或摩擦均不敏感, 但在高温、高压和有可被氧化的物质(还原剂)存在 及电火花下会发生爆炸, 在生产、咜运和使用中必须严格遵守安全规定 ${ }^{[12]}$ 。然而, 在这起事故中, 由于当地缺乏有效的治理和法制约束, 事故仓库令人震惊地将爆炸物与巨量具有爆炸风险的硝酸铵 共同储存, 严重违反安全规定。而当地政府多名高级官员在多次收到港口存放危险品的报告之后, 缺乏敏感和警惕, 未采取任何应对措施。最终根据当地司法部门的调查, 包括政府总理和三名前部 长在内的三十多人因玩忽职守等罪名被起诉, 我们可以想见当地港口管理人员、海关和政府对危险 化学品的管理知识必然非常贵乏且毫无警惕, 他们面对当地法律的约束也显得十分淡漠。

通过案例分析, 我们向学生强调, 在我国对于涉及危险化学品的生产、储存、经营、使用、运 输和登记等方面的问题, 主要有《安全生产法》 ${ }^{[13]}$ 和《危险化学品安全管理条例》 ${ }^{[14]}$ 等规定。近年 来, 我国不断夯实安全生产责任, 与化学品有关的安全生产事故发生已经得到了有效控制, 但是想 要彻底消除事故的阴䨪, 从黎巴嫩的事故我们可以吸取的教训是我国需要在各行各业培养一批具有 较高思想道德素养且对化学品安全问题敏感的从业者。

两起典型事件警醒了我们, 化学品的非法添加、滥用和违规储存等问题对人民群众造成的伤害 是巨大的, 甚至可能引发整个社会的严重动荡。法律来自于社会的实践, 我们的国家立法建立在我 们的国情之上, 建立在各领域的现状之上, 具有其充分的合理性、底线性, 违背了法律与法治也就 等于违背了生产的基本规律, 必然要遭到反噬。透过这样两起事件, 我们会发现如果化学的相关行 业的参与者、经营者甚至监管者不懂化学知识, 没有对他们所使用的、经营的、监管的化学品的危 害有所了解, 更没有对国家相关的法律和化学品管理的规定有所敬畏, 丧失法治精神, 那么他们就 可能将本可造福于人类文明的化学, 变成伤害文明、战害无幸的屠刀。 


\section{3 以法为圭臬育新人}

习总书记指出 “依法治理是最可靠、最稳定的治理”。科学技术是第一生产力, 但技术是 “双 刃剑”, 我们在化学上取得了长足的进展, 限制也必不可少。河床是对河水的限制, 它为河水定型、 决定了河水的走向、流速。看似是重重阻碍, 可若没有了河床, 流水淙淙又该如何汇聚奔腾? 因此, 限制是为了更好地发展化学，这种限制最关键的因素不仅在于法度，更在于人的内心。

通识课程在大学课程体系中扮演了一个提供多元化和跨学科视角的独特角色 ${ }^{[15,16]}$, 正如我们长 期以来在化学与人类文明这一课程中坚持的理念, 通过化学通识教育使得大学生们离开校园后, 能 够正视化学, 运用化学的眼光看待问题。也希望当他们从事化学相关工作时能够将化学思维与工作 实际相结合, 以法为圭臬, 有所为有所不为。

总结经验, 不难发现许多化学品安全事故的发生都存在从业者对化学品的危险缺乏警惕性、法 治意识淡薄的问题, 以致利欲熏心岡顾法度, 使得化学由造福成了造祸。我们选取 “三聚氰胺事件” 作为国内极其典型的食品安全事件, 引发了很长一段时间内中国社会各方面的深刻反思, 也促进了 我国奶制品行业向高质量发展的有益转变, 以此作为教学情境, 能够使得学生获得离自己生活比较 贴近的直观感知; 而黎巴嫩首都的爆炸事故则是我们选取的较新的教学案例, 作为一大国际热点问 题, 希望学生居安思危, 从国内外治理比较中感受到全面依法治国和推动国家治理体系和治理能力 现代化的必要性。

结合课程改革的基本方向, 我们在通识课程的教学中坚持建构主义下的学习观, 即通过教师的 案例引入创设情境, 引导学生在合作课堂的教学形式中, 借助教师和同学的帮助, 分为小组, 主动 去查阅相关资料, 联系自己所学习的学科实际, 向同学分享自己的收获, 最终自主建构化学与人类 文明课程的基本知识框架，并且获得思想政治素养的综合提高。

专业的学习教会我们专业的知识, 培养特定行业需要的人才, 例如经济学可以培育出经营者和 企业家, 医学可以培养出医生和护士, 文学可以培育出诗人和作家, 法学可以培育出法官和律师等 等; 而通识的课程则突破专业的限制, 它教给我们另外一些有用的知识, 告诉我们有时无用之用方 为大用。在各学科、各行业联系愈发紧密的今天, 化学并非局限于化学科研和化工生产中, 任何人 都有可能从事与化学相关的工作, 由于化学的学科特殊性, 如果没有强烈的底线思维, 没有法治精 神, 那么化学品滥用和失控的灾难就很有可能发生。我们除了要求学生在课上学习《农产品质量安 全法》《食品安全法》《安全生产法》和《危险化学品安全管理条例》等相关法律法规外, 还要求 学生课后结合自身专业及未来可能从事的职业, 自主学习可能涉及的法律法规, 打好思想上的强心 剂和行为上的预防针。

青年兴则国家兴, 当代大学生作为新时代新青年, 未来将是社会发展的重要力量。化学通识课 程必须牢固坚持思想政治导向, 我们通过融入法治教育和思政教育, 以法为圭臬, 为社会主义育新 人, 将 “知法、懂法、守法”, 以及 “敬畏化学、用好化学、管好化学” 的理念植根在学生的心中。 未来的中国必然是文明的、法治的社会主义现代化强国, 只有把下一代教育好、培养好, 把法治精 神种进每个人心中, 用良法善治去约束, 才能从根本上解决人类文明进步与化学危害性之间的矛盾, 让化学与人类文明和平共处, 让化学继续作为推动人类文明不断发展进步的力量。

\section{4 结语}

思政教育是渗透的、主动接纳的过程。我们力图以化学通识课程一一化学与人类文明为平台, 通过化学与其他专业知识的思维碰撞交融, 不仅利用正面案例, 让当代大学生发现化学的基础性和 重要性, 更综合反面事故分析, 在教学过程中注意培养学生的责任感和法治精神, 在不知不觉中达 到化学、法治与学生所学专业的统一。化学作为基础学科, 其对社会发展的重要性冊庸置疑, 但是 化学品潜在的危险也是难以忽视的, 所以我们希望在社会主义现代化的建设中, 有更多的人能更加 全面地掌握必要的化学思维和法治精神, 让化学变得更加安全、更有益于我们的社会。今天的中国 
或许并不完美, 但当这一代有法治精神的青年进入各行各业, 用好化学思维, 建设明天更加美好的 中国，就是我们化学通识教育的目的。

[1] 中共中央关于全面推进依法治国若干重大问题的决定. [2014-10-29]. http://cpc.people.com.cn/n/2014/1029/c64387-25927606.html

[2] 中共中央关于坚持和完善中国特色社会主义制度推进国家治理体系和治理能力现代化若干重大问题的决定. [2019-11-05]. http://www.gov.cn/zhengce/2019-11/05/content_5449023.htm

[3] 徐伟明, 俞敏强, 章鹏飞. 大学化学, 2013, 28 (1), 10.

[4] 杨天林. 化学与人类文明. 北京: 中国社会科学出版社, 2011.

[5] 王彦广, 吕萍. 化学与人类文明. 杭州: 浙江大学出版社, 2016.

[6] 许家喜. 大学化学, 2009, 24 (1), 66 .

[7] 中华人民共和国农产品质量安全法. [2019-01-17]. http://www.moj.gov.cn/Department/content/2019-01/17/592_226992.html

[8］中华人民共和国食品卫生法. [2005-08-01]. http://www.gov.cn/banshi/2005-08/01/content_18960.htm

[9] 中华人民共和国刑法. [2000-12-06]. http://www.npc.gov.cn/wxzl/wxzl/2000-12/06/content_4379.htm

[10] 中华人民共和国食品安全法. [2015-04-25]. http://www.gov.cn/zhengce/2015-04/25/content_2853643.htm

[11］徐伟明，周玲超，邱化玉，章鹏飞. 教育现代化, 2018, 5 (5), 136.

[12] 黎巴嫩贝鲁特港口爆炸事故情况报告. [2020-08-10]. http://www.ncics.org.cn/xinxizixun/sc/2020-08-10/874.html

[13] 中华人民共和国安全生产法. [2005-08-05]. http://www.gov.cn/banshi/2005-08/05/content_20700.htm

[14]＼cjkstart危险化学品安全管理条例. [2011-03-11]. http://www.gov.cn/flfg/2011-03/11/content_1822902.htm

[15] Zhang, P. F.; Xu, W. M.; Dai, Q. L.; Li, W. M. J. Edu. New Cent. 2016, 4, 21.

[16] 李岩云. 大学化学, 2020, 35 (9), 58. 